\title{
Self-Concept and Stress among Junior and Senior School Counselors: A Comparison Case Study in Secondary Schools in Malacca
}

\author{
Roslee Ahmad \\ Faculty of Education, Universiti Teknologi Malaysia, Johor Bahru, Malaysia \\ Email: p-roslee@utm.my \\ Aqeel Khan* \\ ( ${ }^{*}$ Corresponding author) Faculty of Education, Universiti Teknologi Malaysia, Johor Bahru, Malaysia \\ Email:draqeelkhan@gmail.com \\ Mohamed Sharif Mustaffa \\ Faculty of Education, Universiti Teknologi Malaysia, Johor Bahru, Malaysia \\ Email: p-sarif@utm.my
}

Doi:10.5901/mjss.2015.v6n5p593

\begin{abstract}
Counsellors are increasingly burdened with administrative work in school. The pressure of a high workload among counsellors lowers self-concept and job satisfaction. This study aims to explore self-concept and stress in junior and senior counselors in school. Rogers' theory and Boyle's model of teacher stress are fundamental theories. This study used quantitative methods based on a survey technique. The sample included 205 respondents (172 senior and 33 junior counselors) and the data were collected using the Tennessee Self-Concept Scale and Teacher Stress Inventory. The results showed that senior counselors had higher ethical self-concept in terms of family, social, and moral self-concepts compared with junior counselors. In terms of job satisfaction and stress, senior counselors had higher job satisfaction and lower stress than did junior counselors. The results showed there were no significant differences between senior and junior counselors in terms of enforcing school rules, implementation of tasks, interpersonal relationships, and stress. There was no difference between junior and senior counselor in terms of addressing their students' problems.
\end{abstract}

Keywords: Self-concept, Stress, Senior counselors, Junior counselors

\section{Introduction}

The implementation of guidance and counseling services in secondary schools is the beginning of a new era of helping services in the field of education. The role of a counselor in shaping a student's personal life is very important (Khan \& Kalu, (2011). The concept of guiding students to help them acquire further insights, and to make their own decisions in practice, should be given due attention. Othman (2000) states that the duty of counselors or teacher guidance and counseling is to help students develop the ability to make the right decisions through individual or group counseling. Counsellors should have counseling skills and techniques appropriate to the circumstances of their client or group of students.

Changes in the guidance and counseling services syllabus formulated by the Ministry of Education makes reasonable demands for sacrifices in school teachers' guidance and counseling as desired by the National Education Philosophy (FPN) (stakeholders) through the mission and vision of the planned successfully. In addition to those duties, school counselors also run parenting programs and deal with discipline problems, as well as working directly in programs organized by the school such as annual sports, extracurricular activities, canteen day, religious camps, and various other activities. Therefore, school counselors are under pressure to perform their functions in management, administration, and school counseling. Counselors are also obliged to carry the workload required to help implement the subject panel program for students, outdoor events organized by the Parent-Teacher Association, and so on. Therefore, if the burden of continuous duty is not performed by school teachers using the right methods, there will be a negative impact in terms of thinking, behavior, job satisfaction, and self-concept on guidance and counseling. The pressure of these challenging 
tasks and burdens can reduce self-concept and job satisfaction in new or long-serving school counselors, which reduces the quality of their work in this profession (Tamsir, 1998).

\section{Problem Statement}

Nowadays, counsellors are increasingly burdened by the additional duties given to them by the school administration. A high workload is experienced by school counsellors who have to perform extra tasks in addition to their existing official duties. This growing pressure makes school counsellors less motivated or interested, they do not derive satisfaction from their work, and their self-concept is lowered. The relationship between work stress and job satisfaction has been studied among schoolteachers internationally by researchers such as (Boyle et al., 1995; Kyriacou et al., 1978 \& Yanzhen, et al., 2012).

Although stress is inevitable, the extent that stress can affect a person depends on how individuals handle their stress. Each individual has a different perception of stress and act in different ways to handle their stress. Stresses the demand made on the adaptive capacity of the mind and body and explained that if a person is able to handle a stressful request, then the pressure will have a positive impact, and vice versa (David, Fontana, 1989).

Further work is required to explore job satisfaction in the life of an employee, including school counselors. Researchers emphasized that job satisfaction is the most important human need and must be met, particularly to help perfect an individuals' self-concept. Job satisfaction for individuals working as a school counselor with a career in another field is dependent on the amount of work involved in the individual's evaluation of satisfaction. Some individuals derive strength from their work and become satisfied, committed, passionate, and devoted to their job, and accept their duties with full responsibility by their own accord without any coercion (Herzberg, 1959 \& Maslow, A. H. (1970).

Therefore, to achieve the goal of an effective school education system, a school counselor must deal with stress in their acquisition of job satisfaction. A school counsellors should enhance their performance by improving yield and optimal productivity because the increase in job satisfaction is linked to the increased productivity, capacity, and effectiveness of the organization (Gruneberg, 1981).

This study looked at the relationship between new (junior) counsellors and senior counsellors who work at schools. The researchers investigated whether there is any difference in self-concept between junior and senior counsellors and their level of stress. In addition, the researchers also wanted to see whether there were differences in the stress levels between junior and senior counselors based on their length of service.

\section{Objectives}

There were two main objectives: identifying differences in self-concept between junior and senior counselors working in district schools based on gender, and identifying the difference in stress levels between junior and senior counselors who serve in district schools based on their length of service.

\section{Research Questions}

This study explored two research questions: is there a difference in self-concept between junior and senior counselors working in district schools based on their gender? Is there a difference in stress between junior and senior counselors working in district schools based on their length of service?

\section{Research Hypotheses}

Two research hypotheses were explored: that there will be significant differences in self-concept between junior and senior counselors working in district schools based on their gender, and that there is no difference in stress levels between junior and senior counselors working in district schools based on their length of service.

\section{Theoretical Framework}

The study involves two variables that affect the service performed by school counselors: self-concept and stress factors. Rogers (1951) stated that self-concept is self-assessment, other people's assessment of ones' self, and evaluation of other peoples' perceptions towards the individual. This means that an individual's self-concept itself is considered as good and the individual is treated and given the attention according to the good within an environment. According to 
Maslow's hierarchy of needs theory, individuals with a positive self-concept received service and attention from their family, teachers, friends, or neighboring people. These individuals often feel happy, confident, and have full confidence in themselves to do something, are not easily deterred, and are willing to face any challenge and accept their failure calmly. Therefore, these more successful individuals prefer doing simple work that is easy to guarantee success, than the failures of these individuals who have a negative self-concept. Individuals with a negative self-concept tend to spend time with younger individuals who have lower intellectual ability. Sadly, these people are easily manipulated by others. Boyle and colleagues' (1995) model of teacher stress is used as a theoretical basis for this study. This model is widely used to study stress among teachers and contains five factors describing stress symptoms in teachers: workloads, student conduct, professional recognition, classroom resources, and good relationship between colleagues. The teachers' workload and the students' behavior were found to suffer after increased stress levels. Rogers's, (1951) \& Fitts, (1991) stated selfconcept model of teacher stress lay the theoretical foundation for the discussion of the correlation between self-concept and stress in junior and senior counselors.

\section{Method}

This study used data acquired from a questionnaire survey of 77 schools in three districts in the state of Melaka includes Tengah, Alor Gajah, and Jasin districts of Melaka.

\subsection{Sample}

Each of the 77 secondary schools in these three districts has at least two school counsellors, but some schools just have one counsellor because of the relatively few students at the school. There was a maximum of five counsellors in an individual school for up to 2000 students with two school sessions.

The study population consisted of 205 school teachers who also had guidance and counselling duties. The ethnicities of the counselors were Malay, Chinese, Indian and Iban. These were random samples made from a list of counselling school teachers obtained from the Department of Education. The selected counsellor's sample included 205 school teachers: 116 counsellors from Melaka Tengah, 45 people from Alor Gajah, and 44 counselors from Jasin.

\subsection{Research Instruments}

The survey used in this study involved three sets of questionnaires that were divided into two parts: Part A and Part B. Part A explore respondents' personal demographic information such as gender, marital status, and work experience as a counselor. Part B includes two questionnaires: the Tennessee Self-Concept Scale (TSCS) and the Teacher Stress Inventory. The TSCS questionnaire is designed to assess self-concept (Fitts et al., 1991). The TSCS scale measures five subscales of self-concept: family, personal, physical, social, and moral-ethical. This questionnaire has been improved by local researchers with a Cronbach's alpha value of .749 (Yahaya, 2010)

The Teacher Stress Inventory is a questionnaire capturing the stress levels of teachers designed by Boyle et al. 1995. This questionnaire consists of two parts: Cause Stress Index and Stress Level Index. The causes of the level of stress were measured using the factors of school rules, teaching tasks, interpersonal relationships, and students' problem. This questionnaire was validated by the psychotherapy counseling expert at Universiti Teknologi Malaysia in Skudai, Johor, Associate Professor Syed Mohamed Shafeq. This questionnaire was also improved by local researchers with a Cronbach's alpha value of .98 (Azizi, 2010 \& Darman and Mary, 2010) also obtained a Cronbach's alpha reliability of 83 .

\section{Results}

Our sample included 64 male counselors (31.2\%) and 141 female counselors (68.8\%). These statistics show that there are significantly more female counselors than male counselors. One hundred and seventy-two counselors (83.9\%) had less than 15 years of work experience as a counselor, which means that this group largely comprises junior counselors. Meanwhile, 33 counselors (16.1\%) had more than 16 years of experience, which means that this group comprises senior counselors. 
Table 1. Analysis of t-test for Family Self subscale, Personal Self, Physical Self, the Social Self and Moral-Ethical Self based on their gender.

\begin{tabular}{|l|c|c|c|c|}
\hline Subscale Self-concept & Man (Mean) & Woman (Mean) & Value of $\mathrm{t}$ & $\mathrm{p}$ \\
\hline Self Family & 40.11 & 39.86 & $12: 49$ & 0.63 \\
\hline Personal Self & 39.64 & 39.62 & $12: 03$ & 0.98 \\
\hline Physical Self & 38.11 & 38.38 & -0.50 & 0.62 \\
\hline Social Self & 41.75 & 40.50 & $2: 05$ & $\star 12: 04$ \\
\hline Moral-Ethical Self & 38.88 & 38.94 & -0.11 & 0.91 \\
\hline
\end{tabular}

Table 1 shows the results of t-test for self-concept subscale of the Family Self, Personal Self , Physical Self, the Social Self and Moral-Ethical Self.

The t-test results for the self-concept subscale for the family-self showed that mean scores were greater for male counselors ( $M=40.11$ ) than female counselors $(M=39.86)$, which shows greater value is given to male counselors over female counselors. The t-test results for the self-concept of family $(t=0.49, p<.05)$ showed no significant difference between male and female counselors. This finding supports the study by Johari and Pusphavalli (2010), which shows that male counselors assume responsibility in the family, take care with children, and are always positive and optimistic about students' future with realistic advice. This finding also shows that male counselors have higher family values, civic attitudes, responsibility, and creating a harmonious environment than do female counselors.

In the self-concept subscale of personal self, the mean scores are higher for male counselors $(M=39.64)$ than for female counselors $(M=39.62)$, which shows greater value is given to male counselors over female counselors. The t-test results for personal self $(t=0.03, p<.05)$ showed no significant difference between male and female counselors. .

In the self-concept subscale of physical self, the mean scores are very similar between male counselors ( $\mathrm{M}=$ 38.11) and female counselors ( $M=38.38$ ), which shows that the mean value for the physical self in female counselors is slightly higher than for male counselors. The $t$-test results for physical self $(t=-0.05, p<.05)$ showed no significant difference between male and female counselors. This result shows that female counselors are not limited by their physical condition and are able to perform outdoor activities with clients. This means that female counselors were prepared to conduct outdoor activities such as mountain climbing with their clients, to spend the night in a tent, and take their sick clients to the hospital. Female counselors work with full dedication and an optimum workload, which is meaningful to their lives.

In the self-concept subscale for the social self, mean scores for male counselors ( $M=41.75)$ and female counselors $(M=40.50)$ shows that the mean value for the social self in male counselors is higher than in female counselors. The t-test results for social self $(t=2.05, p<.05)$ showed significant differences between male and female counselors. In other words, male and female counselors show differences in their social life, including their relationship with family members, friends, school administrators, students, and others. The higher mean score for male counselors show that they perceive themselves as being loved, favored, and able to easily mix and interact with others more than female counselors do, who tend to focus on emotions or feelings while socializing with others.

In the final self-concept subscale for moral-ethical self, the mean scores are higher for female counselors ( $M=$ 38.94) than for male counselors ( $M=38.88$ ), which shows that the mean value for moral-ethical self is higher for female counselors than for male counselors. The $t$-test results for moral-ethical self $(t=-0.11, p<.05)$ shows no significant difference between male and female counselors because the $p$ value obtained is greater than the value of .05 . The higher mean score for female counselors' means that they are usually more compliant, and fear offending male counselors who do not like the rules, but enjoy their freedom and lack of compliance with their employer's orders.

The t-test results for the Teacher Stress Inventory subscales on the school rules, featured tasks, interpersonal relationships, student problems and job stress as shown in Table 1 show that no subscale has any significant differences between junior and senior counselors.

Table 2. t-test analysis for the subscale of School, Features Tasks, Interpersonal Relations, The Pupil and Work Stress based on length of service.

\begin{tabular}{|l|c|c|c|c|}
\hline Subscale Stress & New Counselor (Min) & Senior Counselor (Min) & Value of t & $\mathrm{p}$ \\
\hline School Rules & 28.33 & 28.45 & -0.16 & 0.87 \\
\hline Features Functions & 42.56 & 43.91 & -1.43 & $12: 16$ \\
\hline Interpersonal Relationship & 44.81 & 45.97 & -1.40 & $12: 17$ \\
\hline The Pupil & $22: 02$ & 24.91 & -5.05 & $12: 00$ \\
\hline Stress Jobs & 24.22 & 25.48 & -1.64 & $12: 10$ \\
\hline
\end{tabular}


In the Teacher Stress Inventory subscale for school rules, the mean scores are lower for junior counselors $(M=28.33)$ than for senior counselor shows $(M=28.45)$. The $t$-test results $(t=-0.16, p<.05)$ show that the school rules subscale was not significant and there is no difference between junior and senior counselors. Counselors are important because they help students become self-disciplined and reduce their problems. Counselors should be good role models for students and prevent them from any disciplinary problems. The longer service of senior counselors shows more maturity and compliance with the school rules.

In the Teacher Stress Inventory subscale for Features Tasks, the mean scores are lower for junior counselors ( $M=$ 42.56) than for senior counselors $(M=43.91)$. The $t$-test results $(t=-1.43, p<.05)$ show no significant differences between junior and senior counselors in this subscale because the $p$ value is $.16>.05$.

In the Teacher Stress Inventory subscale for Interpersonal Relations, the mean score for junior counselors ( $\mathrm{M}=$ 44.81) was lower than for senior counselor $(M=45.97)$. The $t$-test results $(t=-1.40, p<.05)$ show significant differences in the Interpersonal Relations subscale between junior and senior counselors.

In the Teacher Stress Inventory subscale for The Pupil, the mean values for junior counselors $(M=22.02)$ are lower than for senor counselors $(M=24.91)$. The t-test results $(t=-5.05, p<.05)$ show significant differences in the The Pupil subscale between junior and senior counselors.

In the last subscale for the Teacher Stress Inventory, work stress showed mean scores for junior counselors ( $\mathrm{M}=$ 24.22) were lower than for senior counselor $(M=25.48)$. The $t$-test $(t=-1.64, p<.05)$ shows no significant difference in Work Stress between the new counselor and senior counselors.

\section{Discussion and Conclusion}

The findings of this study show that the self-concept of junior and senior counselors in all the self-concept subscale items, family, personal, social, physical, and moral-ethical, show a strong correlation with the counselors' job satisfaction and stress levels. In all the subscales for self-concept, social-self showed higher mean scores followed by the factors of family, personal, moral-ethical, and physical.

Job satisfaction will influence an employee's decision whether to stop or stay in their profession when it involves income (McBride, 1992; Nienhuis et al 1994; Mallam, 1994 \& Hagedorn, 1996).

The results showed that a total of 146 counselors found their wages to be acceptable and adequate to their tasks and positions. Counselors play an important role in the school because they improve the physical, emotional, spiritual, intellectual, and personal development of students. Nevertheless, the inconsistencies and challenges experienced during work have put pressure on counselors. According to previous research, some teachers are feeling pressured to make a decision to quit or retire early before they reach retirement age because of job dissatisfaction owing to the changing nature of their role at work and increased workload in high school (Yifan, 2013).

This study concludes that the self-concept of junior and senior counselors is at an average level. The study also showed that a counselor at schools in the state of Malacca experience less stress while on duty regardless of their age and length of service. Factors contributing a significant influence to job satisfaction are supervision, promotion, and income, which all have an impact on stress levels among male and female counselors.

\section{Acknowledgments}

The authors would like to thank the Universiti Teknologi Malaysia (UTM) and Ministry of Education Malaysia (MOE) Malaysia for their support in making this project possible.

\section{References}

Khan, A., and Kalu, O.C (2011). Psychology and counseling responsibilities for continuous assessment in Malaysian school system. Scientific Research and Essays, 6, 2259-2263.

Othman, M. (2000). Principles of Psychotherapy and Management in Counselling. Universiti Putra Malaysia: Serdang, Selangor.

Tamsir, J. (1998). Job Satisfaction Among Administrative Assistant (Clerical \& Operations) at Universiti Putra Malaysia. Masters project report, Universiti Pertanian Malaysia.

Boyle G. J., Borg, MG., Fazlon, J.M., and Baglioni A. J Jr (1995). A Structural Model Of Dimensions Of Teacher Stress. British Journal of Educational Psychology, 6, 3271-286.

Kyriacou, C., and Sutcliffe J. (1978). Teacher Stress: PREVALENCE, sources and symptoms. Physology British Journal of Education, 48, 159-167.

Yanzhen, T., Quan, S., Jing, F., and Paul, K. (2012). Stress-Lifetime Joint Distribution Model for Performance Degradation Failure. 
Information, 15, 12 5839-5846.

David, Fontana. (1989). Problems in Practice Managing Stress: Cardiff. John Wiley \& Sons, Inc.

Herzberg. (1959). The Motivation to Work: New York, John Wiley \& Sons, Inc.

Maslow, A. H. (1970). Motivation and Personality. New York: Harper \& Row Publisher.

Gruneberg, M.M. (1981). Understanding Job Satisfaction. London: Macmillan Press Ltd.

Rogers, C. (1951). Client Centered Therapy: Its Current Practice, Implication and Theory. London: Constable.

Boyle, G. J., Borg, M. G., Falzon, J. M., and Baglioni Jr., A. J. (1995). A structural model of the dimensions of teacher stress. British Journal of Educational Psychology, 65, , 49-67.

Fitts, W. H. (1991). Tennessee Self Concept Scale, Manual. Los Angelas. Western Psychological Services.

Yahaya, A., Ismail, S., Abdul, A.H., and Ma'alip, H. (2010). Relationships between Self-Concept and Communication Academic Achievement in High School Students in Johor Bahru: Master's Thesis.

Azizi, Yahaya., Shahrin, Hashim., and Tee, Sook Kim., Occupational Stress Among Technical Teachers In Technical Schools in Johore, Malacca and Negeri Sembilan.: Master's Thesis.

Darman, A., and Mariam, Aziz. (2010). Stress Among Teachers in two national seminary in Skudai, Universiti Teknologi Malaysia. Thesis.

Johari, H., and Pusphavalli, a/p Rajoo. (2010). Relationship between Self-Concept and Well Being Among Adolescents Living End, Universiti Teknologi Malaysia. Master's Thesis.

McBride, SA, Munday, RG., and Tunnell, J. (1992). Community college faculty job satisfaction and propensity to leave. Community/Junior College Quarterly of Research and Practice, 16, 157-165.

Nienhuis, R. W. (1994). Satisfied Involved faculty and chairpersons: Keys to faculty retention. Paper presented at the 19th Annual Meeting of the Association for the Study of Higher Education, Tucson.

Mallam, U. (1994). A national research study on factors influencing faculty turnover at selected Nigerian Colleges of Technology I polytechnics. Higher Education, 27, 229-238.

Hagedorn, L.S. (1996). Wage equity and female job satisfaction: The role of wage differentials in a job satisfaction causal model. Research in Higher Education, 37, 5, 569-598.

Yifan, Wang. (2013). A Statistical Analysis on Job Stress and Job Burnout of Senior High School Teachers in Xinjiang. Information, 16, 2 1151-1158. 
ISSN 2039-2117 (online)

ISSN 2039-9340 (print)
Mediterranean Journal of Social Sciences MCSER Publishing, Rome-Italy
Vol 6 No 5 September 2015 